\title{
LIBERDADE ESCLARECIDA: A FORMAÇÃO DE PROFESSORES NOS ANOS 1930
}

\author{
Regina Cândida Ellero Gualtieri ${ }^{1}$
}

\section{RESUMO}

Os temas considerados importantes para o exercício da docência, no início dos anos 1930, abordados na Revista Escola Nova, são analisados com o intuito de caracterizar as orientações pedagógicas oferecidas, na época, pelo Estado aos professores. Trata-se de uma publicação oficial, editada em São Paulo pela Diretoria da Instrução Pública, no período assinalado, e concebida para apoiar tecnicamente os professores em seus fazeres e, sobretudo, esclarecer os fundamentos da reforma educacional em curso. Nessa época, o diretor da Instrução Pública de São Paulo era o escolanovista Lourenço Filho (1897-1970), responsável pelas diretrizes e pela implementação da reforma. A análise dos conteúdos revela um conjunto de princípios, normas e prescrições que visavam estabelecer condutas, modos de ver a escola e de praticar o ensino que, no dizer de Lourenço Filho, compunham a "nascente cultura pedagógica nacional". O propósito dessa análise é também refletir sobre a persistência, ou não, de certos traços desse ideário nas práticas escolares atuais. Palavras-chave: Periódico Educacional; Formação de Professores; Escola Nova.

\section{ENLIGHTENED FREEDOM: TEACHER TRAINING IN THE 1930S}

\begin{abstract}
Subjects considered important for teaching in the beginning of the 1930s, which were found in the Revista Escola Nova, are analyzed to characterize pedagogical orientations offered at that time by the State. It was an official publication edited in São Paulo in that period, conceived to provide technical support to teachers in their work and, above all, to orient them on the foundations of the ongoing educational reform. At that time the director of Public Instruction was Lourenço Filho (1897-1970), a New School follower who answered for the reform direction and application. The analysis of Revista reveals a row of principles, norms and prescriptions which aim to establish proceedings, ways to see the school, to conduct the teaching that, in the words of Lourenço Filho, were part of a "brand new national pedagogical culture". The purpose of this analysis is as well to reflect upon the eventual persistency of certain features of these ideas in today school proceedings.
\end{abstract}

Keywords: Educational Journal; Teacher Education; New School.

As revistas de ensino representaram e representam até hoje um significativo papel na popularização de ideias pedagógicas, de maneiras de ensinar, de inovações curriculares, de uma ideologia educacional e, por isso, constituem fonte documental para a pesquisa histórica. Caspard, P. e Caspard, P. (2002) ressaltam seu valor como instrumento de formação contínua dos professores e é sob essa ótica que o presente artigo analisa a Revista Escola Nova: tomando-a como um instrumento oficial para difundir ideias educacionais, instaurar ou consolidar práticas pedagógicas e guiar os professores em sua ação cotidiana.

Essa publicação já foi objeto de detida análise por Mate (2002), em estudo sobre a natureza da modernização pretendida pelas reformas educacionais escolanovistas. Ao 
examiná-la, aponta o papel que esse veículo desempenhou na formulação de ideias, conceitos, práticas que embasariam novos fazeres pedagógicos. A análise do conteúdo da revista contribui para a autora demonstrar sua tese central de que nos anos 1920 e 1930 estão assentados os pilares de formas de administrar a escola e de praticar o ensino, desenhadas pela racionalidade técnica que, por sua vez, estava fundada em normas científicas. Formas que se mantém atuais, conclui a pesquisadora, mas naturalizadas, sem o reconhecimento de seu caráter histórico.

Assim, revisitar essa publicação do início dos anos 1930 tem o propósito de contribuir para ampliar a caracterização dessas formas de administrar a escola e de nela ensinar; formas que estão na origem da consolidação dos sistemas educacionais no Brasil. Tal caracterização pode nos ajudar a desnaturalizar realidades e pensar certo futuro do passado que se tornou nosso presente.

\section{Brasil novo, escola nova}

A Revista Escola Nova (REN), publicação da Diretoria da Instrução Pública do Estado de São Paulo, integrava o conjunto de ações para a reforma do ensino concebida, no início da década de 1930, pela diretoria da instrução pública paulista, sob o comando do escolanovista Lourenço Filho (1897-1970). ${ }^{2}$ Essa publicação deu continuidade a outra revista, também impressa pela diretoria, intitulada "Educação", então renomeada e identificada como sua "segunda fase".

De acordo com o editor, o próprio diretor da instrução pública, a revista prestaria assistência técnica aos professores, oferecendo por baixo preço uma coleção de monografias. (REN, 1930, V.I, n. 1, p. 280). A proposta era estimular o professor a estudar e auxiliá-lo em suas escolhas didáticas o que era coerente com a convicção de Lourenço Filho e de escolanovistas da época, de que a docência deveria ser exercida com liberdade de cátedra; ele escrevia que, para educar, era preciso liberdade. Entretanto, ressalvava, que a liberdade deveria ser "esclarecida pelo conhecimento". (REN, 1930, V.I, n. 1, p.6) A análise da publicação permite identificar o que deveria constar desse processo de "esclarecimento" dos professores e da cultura pedagógica denominada pelo editor como "nascente" e "nacional" e em correspondência com a "cultura pedagógica mundial".

Entre 1930 e 1931, período em que Lourenço Filho foi diretor da instrução pública em São Paulo, foram editados dez números da Revista, reunidos em três volumes nos quais foram tratados os seguintes temas gerais: escola nova; programas escolares; saúde; testes e medidas; orientação profissional e cinema na escola. ${ }^{3}$ Os assuntos abordados visavam contribuir para fundamentar a reforma em curso e, simultaneamente, subsidiar sua implementação, como se verá a seguir.

O primeiro número, datado de outubro de 1930, foi organizado para responder à pergunta "o que é escola nova" com textos do próprio Lourenço Filho e de outro escolanovista, Anísio Teixeira (1900-1971).

Lourenço Filho abriu o volume com a afirmação de que "para um Brasil novo, uma escola nova" cujo sentido era duplo. Uma escola nova em oposição à escola existente até aquele momento e, ao mesmo tempo, uma escola que atendesse aos princípios do movimento "escola nova". Em suas palavras:

A escola pública não pode continuar a ser um aparelho formal de alfabetização, ou simples máquinas que prepare alunos para certificados de exames e de 
conclusão de curso, segundo programas elaborados em abstrato, para uma criança ideal, que não existe. [...] Tem que ser um organismo vivo, capaz de refletir o meio, nas suas qualidades, e de cooperar na melhoria dos costumes. Tem que ser um órgão de adaptação e de coordenação. A escola nova deixa de ser a escola do mestre, do inspetor ou do diretor geral, como até agora tem sido, para tornar-se a escola das crianças a que deve servir. [...] De um aparelho formal, rígido, separado da vida real, teremos, pois, que fazer um aparelho flexível, animado por um espírito de finalidade social, sempre presente. A escola nova tem que ser uma escola com alma, a alma do Brasil. (REN, 1930, V. I n.1: 3 e 4) ${ }^{4}$

Ideias do escolanovismo, apregoadas por Lourenço Filho, estavam registradas nessa abertura como educação centrada na criança, não no mestre, e escola articulada à vida real. Havia também dura crítica à escola da Primeira República à qual se atribuía a responsabilidade por um processo de alfabetização que apenas instruía para obtenção de diplomas. Como destaca Carvalho (2003), a representação negativa da alfabetização fazia parte dos principais argumentos construídos para legitimar as reformas pretendidas por escolanovistas, ou porque, na visão de vários deles, a educação produzia semi-alfabetos que sustentavam elites mal preparadas, ou porque a escola não estava cumprindo, de fato, seu papel civilizador de formar cidadãos e não apenas eleitores.

Nessa perspectiva, o "aparelho formal rígido", produtor de semi-alfabetos daria lugar à "escola com alma", um "organismo vivo", "animado por um espírito de finalidade social" e, como tal, capaz de responder às exigências do meio e se revelar "um órgão de adaptação". A argumentação de Lourenço Filho se apoiava em concepção biológica evolutiva, típica do início do século 20.

Em outro trecho, essa concepção aparece de modo ainda mais claro ao retomar as comparações, revelando-se alinhada com a perspectiva segundo a qual a evolução da vida ocorreria aos saltos e não de modo gradual como previa Charles Darwin (1809-1882).

A ideia de evolução lenta e incessante tombou em descrédito. A vida se aperfeiçoa por transformações súbitas, no aglomerado de células ou no aglomerado humano. O Brasil retoma de um salto, o lugar que lhe competia na conquista da civilização. A vida brasileira ganhou um novo "sentido". (REN, 1930, V. I n. 1, p.5)

Tal entendimento, transferido para a vida social, permitia antever que o processo de transformação da sociedade, auxiliado por essa escola "animada", seria súbito. O referencial evolutivo não gradualista sustentava, assim, uma compreensão otimista do desenvolvimento da nação. Acrescente-se a isso, como bem analisa Mate (2002), que o tom entusiasta de Lourenço Filho era expressão da legitimidade que conferia à "revolução de 30" e ao governo Vargas que se iniciava e, na avaliação do escolanovista, dava à vida brasileira "um novo "sentido"".

Anísio Teixeira também destacou a ideia de que a escola precisava mudar, mas sua análise situava a mudança em função da necessidade dessa instituição ter de acompanhar um mundo que se transformava rapidamente em decorrência das aplicações da ciência. Isso produzia nova mentalidade em que as coisas deixavam de ser vistas como estáveis e permanentes.

Tudo está a mudar a se transformar. Não há alvo fixo. A experimentação científica é um método de progresso literalmente ilimitado. [...] Tudo que ele (o homem) faz é um simples ensaio. Amanhã será diferente. Ele ganhou o hábito de 
mudar, transformar-se, de "progredir", como se diz. E essa mudança e esse "progresso", o homem moderno o sente. (REN, 1930, V. I n. 1, p. 9)

A percepção de que a sociedade estava em acelerada mudança era a principal razão para desqualificar a velha escola que, segundo afirmava, orientava-se por uma ordem estática e, por isso, preparava a criança para cumprir seu papel na vida adulta, que, em essência, seria o mesmo de seus pais. A essa visão, contrapunha, "temos de construir a nossa escola, não como preparação para um futuro conhecido, mas para um futuro rigorosamente imprevisível”. (REN, 1930, V. I n. 1, p. 16 e p. 10)

Educar para o imprevisível demandava, na visão de Anísio, ações opostas às praticadas pela velha escola que ensinava, suplementando com informações a educação que família e comunidade davam ao indivíduo e preparando-o para "seguir" e "obedecer". E sobre esses aspectos, tecia seus comentários críticos.

A escola não deveria permanecer na posição de suplementar a formação da criança recebida na família e na comunidade. As mudanças sociais impunham à escola assumir para si as funções da família e do meio social e assim justificava:

Em centros muito adiantados, o antigo lar, tão decantado, não é mais do que o "lugar onde alguns indivíduos voltam, à noite, para dormir". [...] hoje a vida de família se desintegrou na sua harmonia de agencia educadora e a vida social tornou-se tão eminentemente complexa que oferece à criança, para sua visão e análise, apenas aspectos fragmentários do seu todo (...). A necessidade, pois, da escola tomar em grande parte, a si, as funções da família e do meio social corresponde a uma verdadeira premência dos nossos tempos, se quisermos os dar às nossas crianças uma chance de se adaptarem e se ajustarem à ordem social do nosso vertiginoso presente. (REN, 1930, V. I n. 1, p. 13 e 17)

Argumentava também sobre a importância de romper com a perspectiva de formar para "seguir e obedecer", pois a nova formação humana, dizia Anísio, tem de preparar para a democracia que exige "personalidade e cooperação". Era necessário que cada homem tivesse "as qualidades de um leader" e ser responsável pelo bem social e, para isso, a escola teria de "educar em vez de instruir" e isso implicava "formar homens livres em vez de homens dóceis"; "preparar para um futuro incerto e desconhecido em vez de transmitir um passado fixo"; "ensinar a viver com mais inteligência [...] em vez de ensinar dois ou três instrumentos de cultura e alguns manuaizinhos escolares". (REN, 1930, V. I n. 1, p.18)

Essa "nova formação" pressupunha reconceber o significado da aprendizagem que deveria deixar de ser entendida como processo passivo, resultante da "absorção" de conhecimentos, mas algo que decorria de ação protagonista do aluno como se pode depreender das palavras de Anísio.

Aprender significa ganhar um modo de agir [...] Aprender significa a aquisição de uma determinada habilidade. Mas, uma ideia? Aprende-se uma ideia ganhando um novo modo de proceder ou agir? É exatamente isso que se dá. Nós aprendemos quando assimilamos uma coisa de tal jeito, que chegado o momento oportuno nós sabemos agir de acordo com o aprendido. (...) o que aprendemos é sempre uma forma especial de reação. [...] Logo, não se aprende senão aquilo que se pratica. Aprender é um processo ativo [...]. Não se aprende por simples absorção. [...] Aprendemos aquilo que nos dá prazer ou satisfação. [...] O desejo do aluno, o seu interesse, para usar a palavra consagrada, orienta o que se vai aprender. (REN, 1930, V. I n. 1, p.20 e 22 e 23) 
Mesmo partindo de parâmetros analíticos diferentes, ambos os textos procuravam convencer o leitor de que a escola precisava se transformar, fosse para contribuir para o processo evolutivo que levaria o país ao lugar que lhe competia, fosse para atender às exigências de um mundo tornado imprevisível em função de constantes mudanças decorrentes de avanços técnicos e científicos. Essa introdução preparou o caminho para que, na sequência dos artigos, fossem discutidos o conteúdo e a forma das transformações escolares que seriam explicitadas aos professores como parte do processo de esclarecimento. E, como constitutivo importante dessas transformações estava a elaboração dos programas escolares com as perguntas nela implicadas, isto é, o que ensinar e, principalmente, quem deveria estabelecer o que seria ensinado, perguntas que a Revista pretendia responder de modo associado ao princípio da autonomia didática, assunto extensamente explorado.

\section{Quem deve escrever os programas escolares?}

No dizer de Lourenço Filho, tratava-se de uma "verdade elementar" o fato de que cada mestre executava apenas os programas que fossem "revelação de sua inteligência, de seus conhecimentos sistematizados, de seus pendores, de sua personalidade, enfim". (REN, 1930, V. I. n. 2 e 3, p. 81). Assim, sua ideia, alinhada com princípios do escolanovismo, era a de que os professores apresentassem seus próprios programas e se dispunha a subsidiá-los em suas escolhas, trazendo ao conhecimento deles programas escolares de vários países e de alguns estados brasileiros.

Reiterando a finalidade da Revista de fornecer "elementos de estudo", Lourenço Filho se dirigiu ao leitor para informar que, aquele número do volume I da Escola Nova havia juntado programas "com orientação das mais diversas" e, desse modo, "ao lado de sugestões e princípios da escola renovada", seriam encontrados "programas de velhos países europeus, alguns de orientação educativa evidentemente tradicional”. (REN, 1930, V. I n. 2 e $3: 85$ )

Essa aparente tolerância não se revela descabida, se for compreendida a partir das convicções de Lourenço Filho, para quem, o programa da escola pública deveria permitir "o aproveitamento das tendências e aptidões especiais de cada educando" e, por isso, programas não rígidos. Mas, simultaneamente, deveria garantir o que denominou "programa mínimo", que toda escola deveria prover:

as técnicas fundamentais de leitura, escrita e cálculo, os hábitos da higiene ou de defesa da saúde, as normas de polidez, as noções gerais de vida doméstica e social, a compreensão dos direitos e deveres cívicos (digamos, assim, o hábito de pensar como brasileiro) tudo isso deve ser comum a todas as escolas, ao ensino de todos os mestres. Isso, e tão somente isso, é o que deve ser fixado. (REN, 1930, V. I n. 2 e 3: 83)

Quando analisamos os planos de ensino de países considerados tradicionais, pela Revista, como o da escola francesa, é possível encontrar elementos para o programa mínimo de que falava Lourenço Filho e isso constituiria subsídios para os professores em São Paulo. Ao mesmo tempo, eles poderiam ler nas páginas da Escola Nova como se organizava o "programa avançado" da escola experimental Francis Parker, de Chicago, ou 
das escolas prussianas, austríacas e brasileiras do Distrito Federal, também apontados como dos mais adiantados em matéria pedagógica. (REN, 1930, V. I n. 2 e 3: 85, 98, 100)

O conteúdo desse número da Revista torna-se ainda mais significativo para os propósitos deste artigo, se os textos publicados forem percebidos tal como designam Carvalho e Toledo (2007, p.90), isto é, "como produtos de estratégias editoriais em complexa correspondência com estratégias políticas e pedagógicas determinadas".

Assim, Lourenço Filho assumiu a diretoria em 1930, momento politicamente agitado em que enfrentou uma situação bem descrita por Almeida Junior:

As aulas - paradas; os estabelecimentos escolares - ocupados por tropas invasoras; juntas governativas locais, geradas espontaneamente, a denunciar professores, a exonerar e a preencher vagas; estudantes do ensino médios a reclamar promoções por decreto. (ALMEIDA JUNIOR, 1959, p. 42)

Considerando o contexto do administrador, Almeida Junior perguntava: "como impor aos professores uma técnica que eles desconhecem? Como exigi-la sem prévia adesão interior da parte deles?" Seu entendimento foi de que "a fim de preparar essa adesão e de incentivar o estudo, Lourenço Filho solicitou que cada professor apresentasse o seu próprio programa, "dentro dos velhos ou dos novos moldes"'. E só depois disso, o então diretor geral "iniciou a catequese através da Escola Nova". (ALMEIDA JUNIOR, 1959, p. 43)

De fato, a Revista revela um percurso catequético, que começava por esmiuçar programas escolares da Alemanha, Áustria, França, Suíça, Itália, de Chicago, de Minas Gerais e do Distrito Federal; seguia apresentando as contribuições de educadores brasileiros - professores ou inspetores escolares - que escreviam sobre a reforma dos programas para apoiar o ensino renovado. Oferecia ainda uma resenha do livro de John Dewey "Vida e Educação", tratando de temas de interesse da escola nova, ${ }^{5} \mathrm{e}$, por fím, um conjunto de pequenos artigos, já publicados em jornais de São Paulo, em torno da autonomia didática, também de autoria de professores e diretores escolares que tentavam explicar o assunto considerado "mal compreendido". Houve publicação com esse teor tanto no número 1 quanto nos números 2 e 3 do Volume I.

O conteúdo deles permite afirmar que esses artigos funcionavam como reforço à posição da administração central, pois não havia vozes dissonantes, mas apenas as que subscreviam aquela posição. Na reprodução do texto, publicado no Correio da Tarde de São Paulo, é perceptível o empenho do jornal para apoiar a reforma, quando afirmou procurar esclarecer aquilo que estava sendo "mal compreendido por grande parte do magistério", no caso, a autonomia didática. Os convocados para essa tarefa foram diretores e professores. É possível especular que a elaboração de programas não era tradição dos professores e isso poderia gerar insegurança, pois houve insistência em reafirmar a importância da liberdade e da criatividade, embora naquela perspectiva do esclarecimento. Assim, Romeu Camargo, diretor de um grupo escolar e um dos convocados para elucidar a questão, relembrou as palavras de Lourenço Filho, quando disse "a obra da educação é, antes de tudo, uma obra de liberdade. Sem ela, não há professor capaz, mas entendamo-nos. Liberdade esclarecida pelo conhecimento, não embrutecida pela superstição e pela rotina." (REN, 1930, Vol. I, n. 2 e 3, p. 294) 
Com a mesma intenção, o Secretário do Interior, Dr. José Carlos de Macedo Soares, em entrevista publicada no jornal $O$ Estado de $S$. Paulo, e também reproduzida na Revista, afirmava:

Queremos incentivar o estudo dos professores, por um serviço de assistência técnica, sem imposição de processos rígidos, como até agora se fazia. O mestre precisa pensar e criar por si. Precisa ter autonomia didática, dentro, está claro, das boas normas da eficiência e do respeito dos princípios científicos. (REN, 1930, Vol. I n. 1, p. 76)

Reforçava-se, com isso, a ideia de que a liberdade fosse iluminada pelo conhecimento, parametrizada pelas "normas da eficiência" e pelos "princípios científicos", conforme advertia o Secretário. Na Revista, os volumes II e III apresentaram esses parâmetros estabelecidos a partir de conhecimentos como a saúde da criança, os testes e medidas ou o uso do cinema educativo.

\section{O estudo científico das crianças}

Os testes e medidas foram objeto de discussão de dois números do volume II. Apresentados como eficazes, os testes, na visão de Lourenço Filho, permitiam avaliar os níveis de desenvolvimento e aptidão da criança de modo "preciso" e "impessoal", bem como realizar diagnósticos "em poucos minutos" e classificar alunos "de modo perfeito" a ponto de propiciar uma antevisão a respeito do destino dos alunos. Uma vez diagnosticados, dizia o editor da Revista, "imaginar-lhes o futuro, não vai senão um passo [...] os mestres sempre procuram medir o que os alunos são como sempre procuram determinar o que eles serão”. (REN, 1931, V.II, n. 3 e 4, p.254 e 255).

Estava ainda em uma fase inicial o uso desses instrumentos, razão pela qual foi recomendado aos professores que aguardassem "modelos e instruções" para sua aplicação, pois faltavam os ajustes necessários.

Se é verdade que fizemos, nos grupos escolares da capital de São Paulo, a maior tentativa de organização psicológica, já realizada na América do Sul, submetendo aos testes A.B.C. para mais de vinte mil crianças (o que permitiu a organização de 468 classes diferenciais) isso se deve a uma circunstância toda fortuita: é que essas provas estavam perfeitamente aferidas para as nossas crianças com base em trabalho de vários anos. Desde já, o serviço de psicologia aplicada ensaia a organização de escalas de velocidade de leitura e cálculo em nossos grupos escolares. Uma larga experimentação já foi iniciada também com os testes de inteligência (...) sem desfalecimentos. (REN, 1931, V.II, n. 3 e 4, p.258-259).

O uso de testes para avaliar inteligência, maturidade ou nível de aprendizagem, como é de amplo conhecimento, foi uma prática corrente nas primeiras décadas do século 20, não apenas no Brasil. Tomados como científicos, constituíam instrumentos que, supostamente, indicavam aos educadores as potencialidades e as limitações dos alunos. Os testes, de fato, funcionavam, lembrando Foucault (2005), como "instrumentos efetivos de formação e de acúmulo de saber", "aparelhos de verificação", "aparelhos de saber". Ou seja, instrumentos de poder, instrumentos para classificar e hierarquizar alunos, para incluílos no processo educacional ou excluí-los.

Ao longo desses dois números do volume II, composto por artigos traduzidos, foram recorrentes as recomendações para que se realizasse um trabalho educacional preciso, 
objetivo, sem erros, como escreveu um dos autores, Alexandre Gali, do Conselho de Pedagogia de Barcelona, um trabalho baseado na "consciência técnica", definida como o "desejo de não se basear em nada do que costuma constituir o orgulho do bom mestre", isto é, "o bom sentido", “a prática”, "o golpe de vista”. (REN, 1931, V.II, n. 3 e 4, p. 267-268) Era preciso, em suma, abandonar a intuição pela consciência técnica.

O mestre está diante de um grupo de alunos. A consciência técnica não se satisfaz com os ver numa certa disposição e associar alguns traços físicos e psicológicos para conhecê-los. Uma boa técnica pedagógica exige um determinado número de dados numéricos individuais e outros coletivos para o grupo em conjunto. Idades cronológicas, idades mentais, pedagógicas, características de ordem psicológica e fisiológica etc., tudo relacionado, classificado, ordenado, estabelecendo índices, coeficientes, proporções e, procurando, por último, os valores médios, os tipos predominantes, os agrupamentos, a dispersão etc. etc. (REN, 1931, V.II, n. 3 e 4, p. 268)

Os textos convenciam o leitor de que o bom professor era o que conhecia "a fundo seus alunos" e disso decorria a importância de que aplicasse os testes para "determinar as aptidões de cada um". Tratava-se de um esforço para instituir a pedagogia objetiva ou científica e torná-la mais eficaz.

Dias (2007) identifica nesse processo características da "pedagogia tecnicista", já que o uso dos testes como também a disponibilização de técnicos para apoiar o trabalho do professor, prevista na Reforma, poderiam ser considerados elementos de uma organização racional que visavam minimizar as interferências subjetivas nas práticas de educar, aumentando sua eficiência. Concordamos que haja pontos de convergência, pois, por exemplo, tanto na Reforma empreendida por Lourenço Filho, quanto nas pedagogias ditas "tecnicistas", a ciência fundamenta as ações. No entanto, não podemos nos esquecer de que alguns princípios defendidos pelo diretor da instrução pública, como a autonomia didática e a possibilidade de o professor eleger seu próprio programa de ensino se distanciam da pedagogia tecnicista tal como caracterizou Saviani (2008). Na proposta de Lourenço Filho, as técnicas e os técnicos conformariam o professor, mas não o substituiriam, pois como já mostrado anteriormente, era convicção do escolanovista, de que cada mestre executava apenas o seu programa, aquilo que fosse "a revelação de sua inteligência, de seus conhecimentos sistematizados, de seus pendores, de sua personalidade, enfim".

Em outro artigo, de autoria de dois professores de Psicologia da Universidade de Ohio, os testes e seus resultados foram mostrados como "fatos indiscutíveis"; "fatos de que tem necessidade um administrador para esclarecer e convencer a opinião pública". Graças aos testes, afirmavam, "a inspeção passa prontamente do domínio da impressão ao da certeza”. (REN, 1931, V.II, n. 3 e 4, p. 322 e 317)

Esses autores não só mostravam a importância do uso dos testes, mas também o que fazer com os produtos.

O primeiro resultado verificado será, sem dúvida alguma, que as crianças, mesmo duma pequena classe, diferem estranhamente: será conveniente, pois, se possível, dividir esta classe em dois ou mais grupos, tomando por base esta diferença de inteligência; os alunos mais brilhantes serão colocados numa divisão de fortes, e os menos bem dotados na divisão dos fracos. (...) um professor deve tirar de todos os seus alunos um rendimento que corresponda às aptidões de cada um deles, o aluno julgado superior deverá fazer trabalho de qualidade superior, e o inferior, trabalho de qualidade inferior. (REN, 1931, V.II, n. 3 e 4, p.314) 
O fato mostrado pelos testes de que as crianças diferiam "estranhamente" e, por isso, aprendiam de modo desigual, foi utilizado para justificar os altos índices de reprovação. Os autores, mesmo declarando que estavam cientes de que havia múltiplas causas para o insucesso, recomendavam aos professores que, em primeiro lugar, verificassem a existência de crianças "anormalmente pouco dotadas", pois, diziam, "um dos resultados mais eloquentes das pesquisas recentemente efetuadas foi revelar a existência de enormes diferenças de escola para escola relativamente à inteligência dos alunos que a frequentam".

Os métodos adotados pelos professores também poderiam explicar a não aprendizagem, mas de acordo com os autores, "nunca antes de haver estudado o problema precedente". O texto ainda advertia sobre a possibilidade de "haver injustiça para com os professores duma escola situada numa zona onde o elemento é de má qualidade", porque "se não se leva em conta o fator inteligência, pode a gente ser levada a atribuir a um mau método de ensino o que em verdade é devido à profunda incapacidade dos alunos". (REN, 1931, V.II, n. 3 e 4, p.317 e 318)

No conjunto dos textos, percebe-se que havia uma ideia considerada importante para ser fixada: a razão do fracasso das crianças deveria ser primeiramente encontrada na baixa inteligência delas. A culpabilização da criança pelo fracasso na escola em virtude de suas pretensas características biológicas, pode ser compreendida em um quadro mais amplo em que a ciência da hereditariedade se desenvolvia, trazendo respaldo para uma crescente valorização do determinismo biológico que, usado como referencial, acabava por estabelecer os limites da ação educacional e justificar o fracasso. As investigações da Genética pareciam mostrar que a educação tinha limites porque o patrimônio genético dos indivíduos estava dado. Lourenço Filho, em texto publicado no final dos anos 1920, já afirmava: "o que a genética vem demonstrar não é, pois, a possibilidade ou a impossibilidade do fato, em si mesmo, mas o limite. O limite da influência do meio e a fatalidade da transmissão hereditária, de sua continuidade biológica strictu sensu". (LOURENÇO FILHO, 1929: 8)

De modo complementar, a psicologia experimental fornecia elementos para o professor avaliar a capacidade dos alunos e conhecer até onde iriam suas possibilidades. $\mathrm{O}$ uso dos testes pretensamente permitiria identificar essas possibilidades. Tratava-se, nessa perspectiva, de instituir a pedagogia científica, a pedagogia referenciada nas ciências, para tornar o ato educativo mais eficaz. $\mathrm{O}$ ato pedagógico cientificamente controlado era condição para resolver os problemas educacionais, sobretudo, o baixo rendimento dos alunos, um dos desafios que o reformador pretendia enfrentar como se pode constatar na entrevista para jornais da época em que chamava a atenção para a existência de escolas com altos índices de repetentes.

Grupos escolares há em São Paulo que apresentam porcentagem maior que cinquenta de alunos repetentes nas duas primeiras classes. Um apresenta $85 \%$ o que é realmente espantoso... com as providências a serem tomadas de organização de classes seletivas, o rendimento do ensino deve crescer pelo menos, de trinta por cento. (REN, 1930, Vol. I, n. 1, p. 279)

A organização de classes seletivas ou classes homogêneas, compostas por alunos com níveis de inteligência semelhantes, ou, como diziam, classes com "uniformidade 
mental" era considerada essencial para solucionar a questão da repetência e dos "retardados pedagógicos" A organização dessas classes seria realizada a partir da aplicação de testes psicológicos, "uma das surpreendentes aplicações da psicologia". (REN, 1930, V. I, no. 2 e 3, p. 279)

Embasado em tais princípios, o uso dos testes tornava legítima a separação dos alunos por suas supostas diferenças de inteligência. Essa separação visava otimizar os processos de aprendizagem, pois evitava a dispersão dos professores com alunos pouco dotados misturados aos bem dotados e possibilitava ensinar cada um, de acordo com sua capacidade revelada pelos testes. Por isso, "medir e avaliar" deveriam substituir o "golpe de vista" do mestre para, com base objetiva e impessoal, ser capaz de selecionar e classificar a criança.

Fernando de Azevedo, escrevendo sobre a Reforma da Instrução Pública do Distrito Federal (que ocorreu no final dos anos 1920), em texto reproduzido na Revista, afirmava:

Não se compreende hoje mais educação sem estudo de psicologia da criança e, sobretudo a psicologia experimental, que dará elementos para o mestre avaliar em linhas gerais a capacidade do aluno e saber até onde vão as suas possibilidades. (REN, 1930, V.I, n. 2 e 3, p.235)

Garantir aos indivíduos o direito a ser educado até onde permitissem suas aptidões naturais era um princípio sagrado dos escolanovistas que foi expresso no célebre "Manifesto dos Pioneiros da Educação Nova", escrito por Azevedo, em 1932. Esse princípio foi apresentado como um avanço porque, na perspectiva desse documento, o processo de escolarização deixava de "constituir um privilégio determinado pela condição econômica e social do indivíduo, para assumir um "caráter biológico"'. (Azevedo, s/d, p. 64) A seleção humana, nessa compreensão, era justificável pelas aptidões naturais, mas não pela condição de classe, daí o denominado "caráter biológico" da educação. Essa ideia estava atrelada à seleção dos mais capazes que deveriam seguir, escolarizando-se, e de onde emergiriam as elites do país. No "Manifesto", está escrito:

Se o problema fundamental das democracias é a educação das massas populares, os melhores e os mais capazes, por seleção, devem formar o vértice de uma pirâmide de base imensa. Certamente, o novo conceito de educação repele as elites formadas artificialmente "por diferenciação econômica" (...) e tanto mais perfeitas serão as sociedades quanto mais pesquisada e selecionada for a sua elite. (AZEVEDO, s/d p. 76).

A seleção dos aptos era fundamental para construir a pirâmide social. E a educação eficaz era a que fosse capaz de estabelecer perfeita correspondência entre a pirâmide escolar e a pirâmide social. Nesse contexto, se entende a expressão criada pelo educador suíço E. Claparède, e utilizada por escolanovistas brasileiros como F. de Azevedo - "a escola sob medida". Ela condensa o princípio de que a cada um é devida a educação que lhe convém. Os referenciais científicos permitiam aos educadores fundamentar esse princípio e popularizar a ideia de que, sendo garantida a igualdade de oportunidades, os mais capazes e determinados se revelariam independentemente da classe social. ${ }^{6}$

Os mais capazes se caracterizavam por terem, além da dotação intelectual, a física e a comportamental. Assim, na "escola sob medida", escreveu Azevedo, além dos normais, dos débeis e dos anormais verdadeiros, também seriam identificados os doentes, os 
desnutridos, os tuberculosos, os deficientes físicos, os pobres para encaminhá-los às clínicas escolares que seriam construídas. (Azevedo, s/d, p.185-187). Com essa perspectiva, a preservação da saúde do indivíduo ganhou relevância na Revista.

No entanto, o foco das orientações era mais amplo do que a preservação da saúde individual e se situava na preservação da saúde como um elemento essencial para a preservação da espécie. Na abertura dos números dedicados à saúde, Lourenço Filho escrevia que a base biológica era "irredutível" e, entendendo dessa forma, enfatizava que não poderia haver preocupação em melhorar a vida, se a vida não existisse ou não oferecesse possibilidades de evolução. A defesa da vida, associando-a à formação de indivíduos sadios completava a preleção. (REN, 1931, V. II, n. 1 e 2, p. 4 e 5).

Esse interesse pela preservação da saúde como condição para a preservação da própria espécie humana é um desdobramento da preocupação apontada por Foucault (2005) com o "corpo múltiplo", com o "corpo com inúmeras cabeças", isto é, a "população". Uma preocupação que toma a população como problema político, científico, biológico, em suma, um problema de poder. No século 19, esse poder, o "biopoder", toma "posse da vida", incumbe-se dela e a tem como objeto e objetivo.

Particularmente, o final do século 19 e o início do século 20 foram um momento de medo e apreensão, por parte das elites de países do mundo ocidental em que se intensificavam os problemas decorrentes dos processos de industrialização e urbanização, tendo como consequência mais pobreza, violência e doenças nos aglomerados humanos. Nesse contexto, surgiu o medo de que a espécie humana degenerasse em função da "superreprodução" dos considerados "mal dotados". A constatação era a de que os pobres, de modo geral, deixavam descendentes em número maior do que os bem sucedidos, do ponto de vista social e econômico, e esse desequilíbrio parecia contrariar a maneira de a seleção natural operar. Na natureza, a regra é que os bons exemplares gerem prole mais numerosa como prova do sucesso. Então, aparentemente, estava ocorrendo uma seleção às avessas e, por isso, o medo da degeneração. Para normalizar essa condição, o ser humano deveria intervir nessa seleção, o que constituiria a eugenia, tema que, na Revista, foi vinculado às questões de saúde.

Assim, para compor o volume referente à saúde, o editor reproduziu um texto apresentado como programa para escolas primárias e normais, assinado por Thomas Wood, dos Estados Unidos. O autor foi categórico, ao afirmar que o ensino da saúde poderia mudar o ambiente atual dos alunos apenas numa extensão limitada, entretanto seria diferente, se se tratasse do melhoramento das condições de vida do futuro. A preparação do futuro incluía a educação eugênica, "um dos métodos necessários de impedir o casamento de incapazes". Wood argumentava que não se tinha a liberdade para escolher os antepassados, porém a educação teria de mostrar a responsabilidade de cada um sobre as gerações futuras e, desse modo, assegurar a toda criança seu direito de "ser bem nascida". (REN, 1931, V. II, n. 1 e 2, p. 24, 32, 43 e 79).

$\mathrm{Na}$ Revista, em volume anterior, um representante do movimento eugênico brasileiro, Octavio Domingues, já havia escrito sobre a eugenia quando resenhou a obra "Vida e Educação", contendo textos de John Dewey. ${ }^{7}$ O autor iniciou seus comentários apontando que

os dois problemas mais graves, que tem a humanidade de resolver (...) são a educação e a eugenia. (...) Sob pena de se ver destruída toda a civilização secularmente acumulada. A insatisfação das massas, as guerras internacionais e 
civis, as lutas econômicas, as crises de toda sorte, a miséria em que vive talvez um terço da população da terra - tudo isso são a consequência de duas coisas: erros na concepção biológica da criança, erros na educação dela. (REN, 1930, V.I, n. 2 e 3, p. 275)

Entre as convicções de Domingues e de eugenistas da época estava a de que o indivíduo "geneticamente mau" não deveria procriar e caberia ao educador convencê-lo disso Em seu livro A hereditariedade em face da educação, publicado em 1929, atribuía à educação o papel de "descobrir as melhores heranças" para que, desse modo, pudessem ser aproveitadas com eficiência máxima "as boas predisposições". (Domingues, 1929, p. 134 e 139). Esse livro inicia com uma epígrafe de Karl Pearson, discípulo de Francis Galton, que dizia: "só aplicada a uma raça de homens inteligentes é que a educação não será de pequeno valor". Os ensinamentos de Domingues contribuíam, sem dúvida, para legitimar a orientação pedagógica de aplicar testes com a finalidade de classificar os alunos e separálos em classes homogêneas.

Identificar as aptidões dos escolares, no entanto, constituiu orientação, nas páginas da Revista, não apenas para organizar classes homogêneas, mas foi também indicado como "de valor inestimável” para orientar a escolha da carreira profissional, tema de preocupação do editor da Revista e de seu programa formativo, ao lado da utilização do audiovisual na escola, em especial, o cinema, os dois últimos assuntos do volume III, editado por Lourenço Filho.

\section{Profissões e inovações educacionais}

Um dos articulistas, médico da Faculdade de Medicina do Rio de Janeiro, chamava a atenção para a importância de serem conhecidas as "tendências" e o "valor intelectual" dos indivíduos para se proceder a uma orientação profissional, pois ,dizia, "se até para o adestramento dos animais tiramos partido de suas tendências, como desprezar nos homens as aptidões naturais de cada um?". Seu recado se voltava basicamente para estimular a realização do "exame psico-fisiológico" na pesquisa das aptidões. (REN, 1931, V III, n. 1, p. 113)

A parte do volume III destinada a tratar da orientação profissional reuniu textos tanto para fundamentar o tema quanto para divulgar as iniciativas que vinham sendo tomadas para otimizar o mundo do trabalho e torná-lo mais eficaz.

Nos anos 1930, os estudos de psicologia aplicada (psicotécnica) passaram a ser utilizados também no ambiente empresarial para lidar com as questões voltadas para a organização do trabalho, a educação e formação profissional. O volume III reproduziu notícias de jornal, como a de autoria de Roberto Mange, professor da Escola Politécnica de São Paulo, que informava sobre as atividades da comissão responsável por escrever o estatuto de uma sociedade destinada a resolver o "problema da racionalização do trabalho". Nessa comissão, tomavam parte o próprio autor do texto, Lourenço Filho, Damasco Penna, entre outros. (REN, 1931, V III, n. 1, p. 127) Tratava-se da discussão do germe que seria o futuro Instituto de Organização Racional do Trabalho (IDORT), criado em meados de 1931 com a missão de cuidar da organização científica do trabalho.

A intelectualidade e os industriais de São Paulo se mobilizaram para usar intensamente os testes na seleção profissional e na organização racional do trabalho, na 
visão de Nunes (1988, p. 12), porque aqui “o universo da produção era mais preciso", mas no Rio, diferentemente, os testes "catalisavam o tema da formação das elites nacionais".

De fato, o envolvimento de Roberto Mange e Lourenço Filho nas questões do ensino profissional, da avaliação das vocações foi uma realidade, mas a ênfase nessas questões não representou o descuido em relação à formação das elites haja vista o caráter extremamente seletivo que a escola paulista teve durante boa parte do século 20 .

Por fim, o processo de esclarecimento dos professores ainda incluiu a sensibilização deles para o uso do cinema no ambiente escolar. A intenção era introduzir mais um elemento que pudesse revolucionar o modelo pedagógico, considerado ultrapassado, centrado unicamente no professor que detinha o monopólio da fala. Além disso, o uso de imagens em movimento seria um avanço, pois ampliava a linguagem imagética estática, comumente utilizada na escola, presente nas pranchas com gravuras e nos livros didáticos.

Nas considerações iniciais do número dedicado ao cinema educativo, Lourenço Filho destacou o uso das projeções como meio e não fim, ou seja, como auxiliar para o ensino das disciplinas e alardeava o fato de que o cinema era uma das "três novas instituições da reforma", ao lado das "associações de Pais e Mestres e das bibliotecas". (REN, 1931, V III, n. 3, p.141 e 142).

Vários professores envolvidos com cinema educativo escreveram para esse número da Revista, como Jonathas Serrano Francisco e Venâncio Filho, professores do colégio Pedro II e autores do livro "Cinema e Educação", publicado em 1930. (REN, 1931, V. III, n. 3, p. 154 - 184). Também constou um artigo de outro autor de livro sobre cinema educativo, "Cinema contra cinema", de 1931, Joaquim Canuto Mendes de Almeida mesmo modo, o autor de, (REN, 1931, V. III, p. 185-200). Nesses textos pode-se encontrar um misto de orientação para o uso do cinema educativo com explicações visando a desmistificar esse uso. O fato, como mostra Carvalhal (2009), é que a crença nessa modernidade tecnológica, por parte dos reformadores, não foi correspondida pelos professores. Eles viam com desconfiança sua eficácia e com apreensão a possibilidade de o cinema falado substituir o professor, diferentemente, dos reformadores que apostavam nesses recursos tecnológicos para as transformações pretendidas. ${ }^{8}$

\section{Futuro do passado}

Quando observamos o conjunto de orientações veiculadas na Revista, apresentadas como essenciais para o "esclarecimento" dos professores, identificamos o que Nóvoa (2002, p. 11) denominou "discursos que exprimem desejos de futuro", ou seja, um conjunto de princípios, normas e prescrições que visavam estabelecer condutas, modos de ver a escola e de praticar o ensino que, no dizer de Lourenço Filho, compunham a "nascente cultura pedagógica nacional". Quais eram esses “desejos"?

Como se viu, a ideia central que norteava a Revista oficial era a de transformação proposta tanto para os fazeres quanto para a mentalidade dos professores. No modo de atuar dos professores, a transformação pressupunha o abandono da intuição que deveria ser substituída pela "consciência técnica", alcançada com o uso do conhecimento científico, dos testes psicológicos e pedagógicos. Esses recursos eram reconhecidos como capazes de "medir o que os alunos são" para "determinar o que eles serão" e, ao mesmo tempo como úteis para organizar "classes seletivas e homogêneas" nas quais a "uniformidade mental" seria a solução para o problema da não aprendizagem e da repetência, pois a cada um seria oferecido o adequado na pretensa "escola sob medida". 
$\mathrm{Na}$ mentalidade do professor, a transformação requeria mudanças no modo de educar as crianças, isto é, educá-las para o "imprevisível", dado que as ciências e a técnica alteravam o mundo rapidamente e de forma incontrolável. Isso exigia outra escola, formadora de "sujeitos autônomos", de "leaders" em lugar daquela voltada para transmitir um "passado estático" e preparar as crianças para "seguir e obedecer".

A transformação pretendida também incidiu sobre a compreensão dos professores relativamente às "novas finalidades sociais da escola". As mudanças na sociedade passaram a exigir da escola um trabalho que não poderia se limitar a "suplementar a educação da família". Diferentemente, apontava para a necessidade de a escola tomar para si "grande parte das funções da família e do meio social", entre as quais, "a defesa da saúde", a socialização das "normas de polidez" e das "noções gerais de vida doméstica e social".

Um conjunto de transformações que seriam induzidas a partir de "saberem autorizados", na expressão de Carvalho (2000), dados a conhecer por processos de formação contínua via impressos, como a Revista e que, entre outras alterações provocadas, estaria a reformulação dos programas a ensinar, de autoria dos próprios professores em respeito à autonomia didática. Autonomia respeitada por princípio, já que, na visão do editor da Revista, a "verdade elementar" ensinava que o mestre executava apenas os programas que fossem "revelação de sua inteligência, de seus conhecimentos sistematizados, de seus pendores, de sua personalidade, enfim".

Certamente, alguns desses "desejos de futuro" identificamos nos modos de ver a escola e no ensino no tempo presente. Alguns deles subsistiram como prescrição, outros se inscreveram e se naturalizaram nas práticas pedagógicas, outros não se realizaram.

A culpabilização das crianças pelo insucesso escolar se mantém nas representações de muitos educadores haja vista a força explicativa dos fatores atribuídos à história pessoal delas. Assim, além de determinantes biológicos, fatores como carência cultural, desestruturação familiar, desinteresse da família, falta de estímulos durante o desenvolvimento, violência doméstica, déficit de atenção são comumente invocados para explicar o mau desempenho.

Em relação à autonomia didática e aos programas escolares, as políticas educacionais vêm oscilando. Ora propõem generalidades, que deixam os professores sem referências reais e solitários em suas decisões. Ora prescrevem orientações minuciosas que acabam por destitui-los de sua função de planejar o ensino e os transformam em tarefeiros. Essa última tendência tem se acentuado nas últimas décadas com a crescente ampliação prescritiva do Estado Pedagogo, na expressão de Lessard (2008).

Quanto a "educar em vez de instruir", "formar homens livres em vez de homens dóceis" são discursos presentes nos atuais documentos oficiais que oferecem parâmetros para o currículo, mas que entram em flagrante contradição com uma organização escolar pensada para a monótona reprodução de saberes e de condutas e não para o protagonismo do aluno e para a dúvida ou o questionamento.

Com os olhos de hoje, podemos considerar que o pretenso "esclarecimento" envolveu orientações contraditórias: equivocadas ao culpabilizarem crianças pelo fracasso escolar, e acertadas, quando afirmavam a importância de se educar para a autonomia e para o imprevisível, ou ainda, que ampliavam as funções sociais da escola, ao levar em conta atribuições da família na era industrial.

No entanto, passados oitenta anos, mantém-se um desafio identificar e superar as razões da persistência de valores discriminatórios que até hoje reverberam na escola, e da continuidade de problemas cujo equacionamento já vem de então. A despeito do discurso 
renovado da academia e de determinadas instâncias administrativas, a atual formação dos professores - inicial ou contínua - não tem bastado para esse propósito, pois isso demanda um programa a ser cumprido e, para tanto, vale lembrar a urgência do alerta de Le Goff (2003), ao dizer que à relação essencial presente-passado deve-se acrescentar o horizonte do futuro.

\section{Referências}

ALMEIDA JUNIOR, Antonio F. de. Formação profissional de Lourenço Filho. In: ASSOCIAÇÃO BRASILEIRA DE EDUCAÇÃO (org.). Um educador brasileiro: Lourenço Filho. São Paulo: Edições Melhoramentos, 1959, pp. 27- 44.

AZEVEDO, Fernando. A Reconstrução educacional do Brasil. Manifesto dos Pioneiros da Educação Nova (1932). In: AZEVEDO, Fernando. A educação entre dois mundos. São Paulo: Edições melhoramentos, s/d, pp. 59-81.

CARVALHAL, Fernanda Caraline de A. Instituto Nacional de Cinema Educativo: da história escrita à história contada - um novo olhar, 2009. Disponível em: http://www.mnemocine.art.br/index.php?option=com_content \&view=article\&id=167:instit utonaccine\&catid=42:historia-no-cinema-historia-do-cinema\&Itemid=67 Acesso em 02-062011

CARVALHO, Marta Maria Chagas de. Molde nacional e fôrma cívica. Higiene, moral e trabalho no projeto da Associação Brasileira de Educação (1924-1931). Bragança Paulista, SP: EDUSF, 1998.

Modernidade pedagógica e modelos de formação docente. In:

Perspectiva. [on-line]. 2000, V.14, n.1, pp. 111-120. Disponível: http://www.scielo.br/pdf/spp/v14n1/9808.pdf. Acesso em 31-05-2011.

Reformas da instrução pública. In: LOPES, Eliane Maria Teixeira; FARIA FILHO, Luciano Mendes; VEIGA, Cynthia Greive. 500 anos de educação no Brasil. Belo Horizonte: Autêntica, 2003. pp. 225-251

CARVALHO, Marta Maria Chagas de C; TOLEDO, Maria Rita de Almeida. Os sentidos da forma: análise material das coleções de Lourenço Filho e Fernando de Azevedo. In: OLIVEIRA, Marcus Aurélio Taborda de (org.). Cinco estudos em História e Historiografia da Educação. Belo Horizonte: Autêntica, 2007, pp. 89-110.

CASPARD, Pierre.; CASPARD, Pénélope. Imprensa pedagógica e formação contínua de professores primários (1815-1939). In: CATANI, Denice Barbara; BASTOS, Maria Helena Camara. Educação em Revista. A imprensa periódica e a história da educação. São Paulo: Escrituras, 2002. pp. 33-46.

DIAS, Enéias Borges. Revista Escola Nova (1930-1931): um estudo sobre o tecnicismo. In: Anais da VII JORNADA DO HISTEDBR, realizado pelo Grupo de Estudos e Pesquisa "História, Sociedade e Educação no Brasil", 2007. Disponível em: 
http://www.histedbr.fae.unicamp.br/acer_histedbr/jornada/jornada7/03trab-autor-E.htm Acesso em 07 de maio de 2011.

DOMINGUES Octavio. A hereditariedade em face da educação. São Paulo: Companhia Melhoramentos, 1929.

FOUCAULT, Michel. Em defesa da sociedade. São Paulo: Martins Fontes, 2005.

Le GOFF, Jacques. História e memória. Campinas, SP: Editora da UNICAMP, 2003.

LESSARD, Claude. Reformas curriculares e trabalho docente: natureza e graus de prescrições do trabalho. In: Revista da FAEEBA. Educação e Contemporaneidade. Salvador, BA: v. 17, n. 30, p. 43-58, jul./dez. 2008.

LOURENÇO FILHO, Manuel Bergstrõm. (1929). "Prefácio". In: DOMINGUES, Octávio. A hereditariedade em face da educação. São Paulo: Companhia Melhoramentos, 1929, pp. 7-9.

MATE, Cecília Hanna. O manifesto dos pioneiros de 32 como ampliação da política reformista. In: 23 ${ }^{\mathbf{a}}$ Reunião Anual da ANPED. Caxambu, MG: Anais do $23^{\mathbf{a}}$ Reunião Anual, 2000. Disponível em www.anped.org.br/reunioes/23/textos/0202t.PDF

. Tempos modernos na escola. Os anos 30 e a racionalização da educação brasileira. Bauru, SP: EDUSC; Brasília, DF: INEP, 2002.

NAGLE, Jorge. Educação e sociedade na Primeira República. São Paulo: Editora da Universidade de são Paulo, 2009.

NÓVOA, Antonio. A imprensa de educação e ensino: concepção e organização do Repertório português. In: CATANI, Denice Barbara.; BASTOS, Maria Helena Camara. Educação em Revista. A imprensa periódica e a história da educação. São Paulo: Escrituras, 2002. pp. 11-31.

Revista Escola Nova. Órgão da Directoria Geral da Instrucção Publica de São Paulo. V. I. 1930, N. 1 a 3; V. II, 1931, n. 1 a 4; V. III, 1931, No. 1 a 3.

SAVIANI, Dermeval. Escola \& Democracia. Campinas, SP: Autores Associados, 2008.

Notas

\footnotetext{
${ }^{1}$ Universidade Federal de São Paulo - UNIFESP regina.gualtieri@ unifesp.br

${ }^{2}$ Além da publicação de uma revista, a reforma previu a criação do serviço de psicologia aplicada para desenvolver estudos e organizar a aplicação de testes de verificação da maturidade das crianças; a restauração das delegacias regionais com o propósito de descentralizar a administração; a instalação de uma biblioteca pedagógica central; a reorganização do ensino normal e profissional. (REN, 1930, V. I n. 2 e 3: 278-282).
} 
${ }^{3}$ A organização foi como segue: volume I -1930 n. 1 - o que é escola nova; 2 e 3 - a questão dos programas; volume II 1931, n. 1e 2 - saúde; 3 e 4 - testes e medidas; volume III - 1931, n. 1 e 2- problema da orientação profissional; n. 3 cinema na escola.

${ }^{4}$ É digna de nota a semelhança dessa afirmação com a que constou no Manifesto dos Pioneiros de 1932. No item "O processo educativo", podemos ler "a escola que tem sido aparelho formal e rígido, sem diferenciação regional, inteiramente desintegrado em relação ao meio social, passará a ser um organismo vivo, com uma estrutura social, organizada à maneira de uma comunidade palpitante pelas soluções de seus problemas." (AZEVEDO, s/d, p. 71). Tal semelhança corrobora a análise de Mate (2000), de acordo com a qual o Manifesto é um documento que sintetiza muitas ideias presentes nas várias reformas que vinham ocorrendo desde os anos 1920.

${ }^{5} \mathrm{Na}$ resenha, o autor menciona que é uma publicação da "Biblioteca da Educação", dirigida por Lourenço Filho, uma tradução feita por Anísio Teixeira de duas obras de Dewey: "A criança e o programa escolar" e "Interesse e Esforço".

${ }^{6}$ Nagle (2009), em relação a esse aspecto, atribuiu essa compreensão como decorrente do "otimismo pedagógico" dos educadores na década de 1920 que acabou por autonomizar o processo educacional em relação ao contexto históricosocial, processo que os impediu de perceber a existência de obstáculos socioeconômicos e, consequentemente, a ineficácia da igualdade de oportunidades. De outro modo, como analisa Carvalho (1998), essa aparente autonomização deve ser entendida que a educação passou, ela própria, a abrigar muitas expectativas de controle e organização social política e econômica. E, não por acaso, questões voltadas para saúde, moral e trabalho constituíam importantes esteios da educação que não se limitava a instruir.

7 São eles: "A criança e o programa escolar" e "Interesse e Esforço"; é uma tradução de Anísio Teixeira, publicação da "Biblioteca da Educação" dirigida por Lourenço Filho.

${ }^{8}$ É digno de nota o investimento nesse recurso representado pela criação do Instituto Nacional de Cinema Educativo, em 1936, no âmbito do Ministério da Educação e Saúde Pública, durante o Governo Getúlio Vargas. Regulamentado pela Lei 378, tinha por atribuições "promover e orientar a utilização da cinematografia, especialmente como processo auxiliar do ensino, e ainda como meio de educação popular em geral”. (CARVALHAL, 2009, p. 4)

Recebido em outubro-2012

Aprovado em julho-2013 